\title{
Studi Kedalaman Perairan Dangkal Berdasarkan Pengolahan Data Satelit Multispektral Worldview-2 di Perairan Pulau Parang Kepulauan Karimunjawa Provinsi Jawa Tengah
}

\author{
Fuji Anida ${ }^{* 1}$, Muhammad Helmi ${ }^{1}$, Kunarso ${ }^{1}$, Anindya Wirasatriya ${ }^{1}$, \\ Warsito Atmodjo ${ }^{1}$, Muh Yusuf ${ }^{1}$ \\ ${ }^{I}$ Departemen Oseanografi, Fakultas Perikanan dan Ilmu Kelautan, Universitas Diponegoro \\ Jl. Prof. H. Sudarto, SH, Tembalang Semarang. 50275 Telp/fax (024)7474698 \\ Email:*fujianida@gmail.com
}

\begin{abstract}
Abstrak
Kondisi kedalaman perairan yang beragam dan dangkal dapat dilakukan menggunakan teknologi penginderaan jauh (remote sensing) dengan bantuan citra satelit. Tujuan penelitian ini adalah mengkaji algoritma berdasarkan rasio saluran spektral terbaik untuk pemetaan kedalaman perairan dangkal menggunakan citra satelit multispektral Worldview-2, mengkaji akurasi pemetaan kedalaman perairan dangkal berdasarkan analisis citra satelit multispketral Worldview-2 terhadap hasil survei kedalaman serta menganalisis spasial kedalaman perairan dangkal berdasarkan hasil analisis citra satelit multipektral Worldview-2. Penggunaan citra satelit Worldview-2 dimana dengan empat saluran multispektral, yaitu band biru pesisir (costal blue), biru (blue), hijau (green) dan kuning (yellow) dikombinasikan menjadi 8 band rasio yang diintegrasikan dengan data kedalaman hasil lapangan 164 data titik sampel untuk pemodelan kedalaman dan 280 data titik sampel untuk uji akurasi dengan rentang kedalaman 0-24 m. Hasil pemodelan memperlihatkan bahwa model empiris batimetri terbaik yaitu rasio band biru dan band hijau dengan perolehan $r$ yaitu 0.8162 . Nilai uji akurasi menggunakan ICC yang diperoleh adalah sebesar $61 \%$ dan menggunakan RMSE sebesar 2.42. Penelitian ini memperlihatkan bahwa perolehan uji akurasi bagus dan band rasio biru / hijau mampu menampilkan kedalaman laut di Pulau Parang, Karimunjawa dari 0 m hingga 18 m.
\end{abstract}

Kata Kunci: Kedalaman, citra satelit Worldview-2, Band rasio, Batimetri, Lyzenga

\begin{abstract}
Diverse and shallow water depth conditions can be done using remote sensing technology with the help of satellite imagery. The purpose of this study is to examine algorithms based on the best spectral channel ratio for shallow water depth mapping using Worldview-2 multispectral satellite imagery, to study the accuracy of shallow water depth mapping based on analysis of Worldview-2 multispketral satellite imagery against depth survey results and to spatial analysis of shallow water depths based on the results. analysis of Worldview-2 multipectral satellite imagery. The use of Worldview-2 satellite imagery where with four multispectral channels, namely the coastal blue band (costal blue), blue (blue), green (green) and yellow (yellow) combined into 8 band ratios which is integrated with the depth of field data 164 point data samples for depth modeling and 280 sample point data for accuracy testing with a depth range of 0-24 $\mathrm{m}$. The modeling results show that the best empirical bathymetry model is the ratio of the blue band and green band with the acquisition of $r$ is 0.8162 . The accuracy test value obtained using the ICC was $61 \%$ and using the RMSE was 2.42. This research shows that the results of the accuracy test are good and the blue / green ratio band is able to show the depth of the sea on Parang Island, Karimunjawa from $0 \mathrm{~m}$ to $18 \mathrm{~m}$.
\end{abstract}

Keywords: Depth, Worldview-2 Satellite Image, Band Ratio, Bathymetry, Lyzenga

\section{PENDAHULUAN}

Indonesia memiliki perairan dangkal yang sangat luas (Ismullah et al, 2018). Perairan dangkal yang luas $(0-5 \mathrm{~m})$ relatif sulit dipetakan dengan metode konvensional melalui survei pemeruman (Arief et al, 2017). Pulau parang memiliki perairan dangkal yang luas dan jernih sehingga ideal untuk melakukan kajian uji kemampuan citra satelit worldview-2 (Hernandez et al, 2016). Pada wilayah 
perairan ini terdapat banyak ekosistem perairan dangkal seperti padang lamun,terumbu karang dan gosong pasir yang menyulitkan akses kapal untuk survei pemeruman (Harianto et al, 2019). Oleh karena itu dilakukan menggunakan tongkat ukur untuk wilayah yang tidak terjangkau oleh kapal. Metode penginderaan jauh memiliki sensor optik dengan kemampuan menembus kolom air di perairan dangkal yang memberikan peluang untuk memetakan perairan dangkal (Shahi et al, 2015). Selain itu metode penginderaan jauh juga memberikan peluang dalam mengukur perairan dangkal karena cepat, murah, efisien, akurat, serta tidak membutuhkan tenaga operasional yang banyak serta kedalaman perairan dangkal merupakan informasi penting dalam alur pelayaran (Eugenio et al, 2015).

\section{MATERI DAN METODE}

Data utama yang digunakan pada penelitian ini yaitu data citra satelit Worldview-2 Pulau Parang perekaman tanggal 29 Oktober 2016 pukul 03.22 WIB dan data pengukuran kedalaman laut melalui pemeruman dan tongkat ukur. Data pendukung yang digunakan yaitu Peta Rupabumi Indonesia (RBI) Pulau Parang, Karimunjawa Skala 1 : 25.000 Publikasi BIG tahun 2019 dan data pasang surut Pulau Parang, Karimunjawa Publikasi BIG bulan November 2019. Penelitian dilakukan di Pulau Parang, Kepulauan Karimunjawa, Provinsi Jawa Tengah.

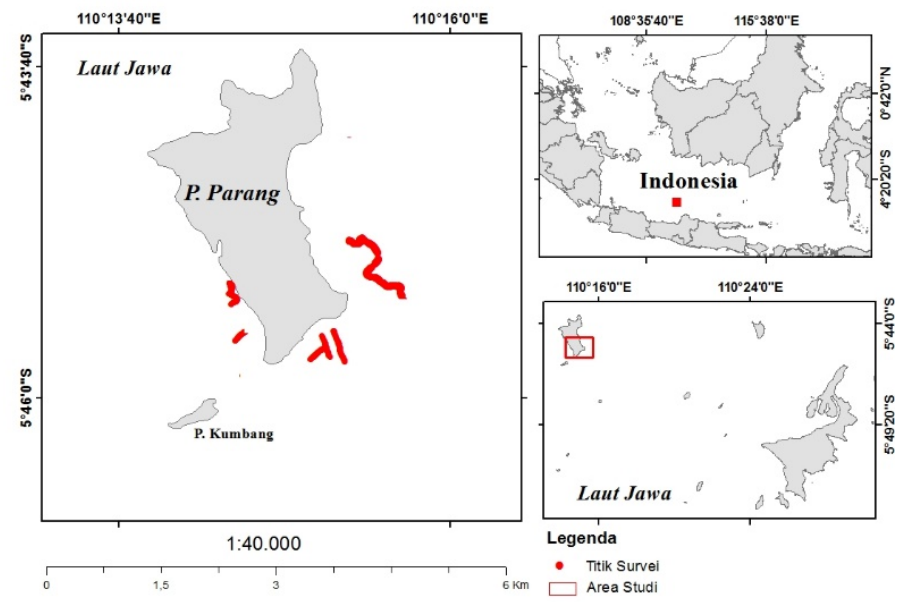

Gambar 1. Peta Lokasi

\section{Pengolahan Data Pasang Surut}

Pengolahan data pasang surut menggunakan metode admiralty, dimana menggunakan data pasang surut 29 hari melalui website ipasoet yang dipublikasi oleh BIG untuk memperoleh nilai MSL, LLWL, HHWL, MLWL, MHWL, Zo dan tipe pasut pada lokasi penelitian (Nurdianti et al., 2016).

\section{Pengolahan Data Kedalaman}

Survei lapangan dilakukan menggunakan singlebeam echosounder dengan jenis GPS Garmin 585 untuk mendapatkan data pemeruman. Selain itu digunakan juga tongkat ukur untuk mendapatkan nilainilai kedalaman yang tidak dapat dijangkau oleh kapal dengan panjang $100 \mathrm{~cm}$. Data yang diperoleh di lapangan selanjutnya dilakukan koreksi menggunakan nilai LLWL (lowest low water level) dan TWLt (true water level time) pada saat perekaman citra. Hal ini guna mendapatkan perubahan pada elevasi muka air yang dilakukan saat pemeruman dan perekaman citra.

Koreksi data lapangan dilakukan dengan nilai LLWL (lowest low water level) dan nilai TWLt (true water level time). Hal ini guna mendapatkan perubahan pada elevasi muka air yang dilakukan saat pemeruman dan perekaman citra. Menurut Soeprapto (2001) dalam Nugraha et al., (2015), reduksi (koreksi) pasang surut laut dirumuskan sebagai berikut: 
$\mathrm{rT}=(\mathrm{TWLt}-(\mathrm{MSL}+\mathrm{Z} 0))$

Dimana :

rT = besarnya reduksi yang diberikan kepada hasil pengukuran kedalaman pada waktu t.

TWLt = kedudukan permukaan laut sebenarnya pada waktu $\mathrm{t}$.

MSL = muka air laut rata-rata.

Z0 = kedalaman muka air surutan di bawah MSL.

Untuk menentukan kedalaman sebenarnya :

$\mathrm{D}=\mathrm{dT}-\mathrm{rT}$

Dimana :

$\mathrm{D}=$ Kedalaman sebenarnya

$\mathrm{dT}=$ kedalaman terkoreksi tranduser

$\mathrm{rT}=$ Koreksi pasang surut pada waktu $\mathrm{t}$

Kondisi dimana adanya perbedaan pengukuran kedalaman dengan perekaman citra sehingga diperlukan koreksi terhadap pasang surut real time, persamaannya adalah :

$\mathrm{Dc}=\mathrm{dT}-\mathrm{rTc}$

Dimana :

$\mathrm{Dc}=$ Kedalaman pada saat perekaman citra

$\mathrm{dT}=$ Kedalaman terkoreksi tranduser

$\mathrm{rTc}=$ Besarnya koreksi hasil pengukuran kedalaman saat perekaman citra

Data pemeruman yang diperoleh merupakan susunan nilai elevasi data titik koordinat baik lintang $(\mathrm{Y})$, bujur (X) dan data kedalaman (Z). Pemeruman dilakukan menggunakan metode random sampling. Metode random sampling adalah pengambilan sampel dari populiasi secara acak berdasarkan frekuensi probabilitas semua anggota populasi. Metode ini dipilih karena diharapkan dapat mewakili beberapa sampel dengan kedalaman yang berbeda - beda.

Hasil data lapangan tesebut dijadikan acuan dalam membangun model estimasi kedalaman dan uji akurasi terhadap hasil pengolahan citra. Dalam hal ini digunakan 164 sampel data untuk pemodelan kedalaman dan 280 sampel data untuk uji akurasi dengan variasi kedalaman yang sama yaitu $0-24 \mathrm{~m}$. Adapun peta lokasi survei untuk membangun model spasial kedalaman dapat dilihat pada gambar dibawah ini.

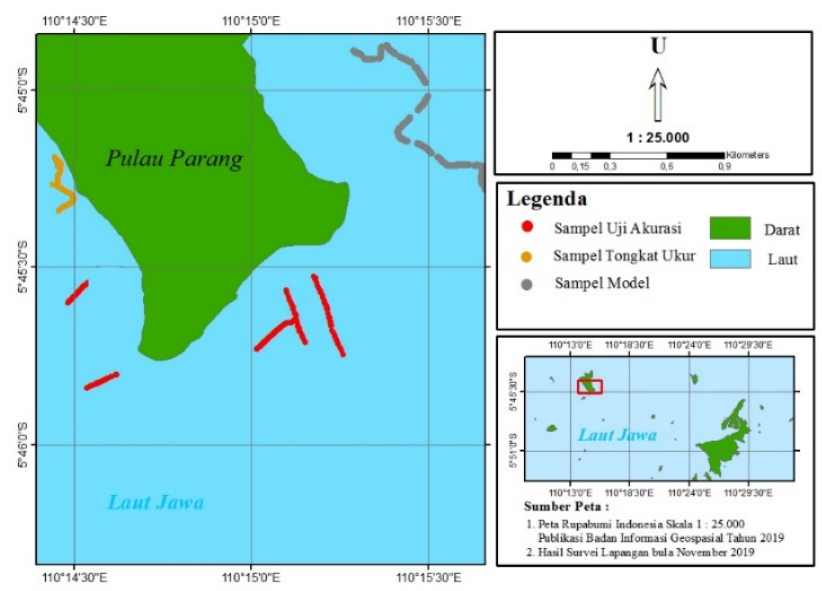

Gambar 2. Peta Titik Sampel Pemeruman dan Tongkat Ukur Pengembangan Model Spasial Kedalaman dan Uji Akurasi Nilai RMSE

\section{Pengolahan Data Multispektral WorldView-2}

a. Koreksi Radiometrik

Citra yang akan digunakan saat ini telah dilakukan koreksi geometrik sehingga selanjutnya dilakukan koreksi radiometrik. Koreksi radiometrik dilakukan dengan mengkonversi nilai piksel 
Worldview-2 ke nilai at sensor reflectance dan kemudian menghilangkan path radiance dengan metode Dark Subtract. Metode ini dilakukan dengan bantuan Software Envi 5.3 dan Envi Classic.

b. Koreksi Sunglint

Koreksi sunglint dilakukan dengan bantuan Software Envi Classic menggunakan band tunggal dan band Nir. Koreksi ini dilakukan agar diperoleh hasil citra yang lebih halus dikarenakan sebelumnya banyak terkena gelombang. Algoritma sunglint oleh Hochberg et al., (2003) yang disempurnakan oleh Hedley et al., (2005) adalah sebagai berikut :

R'i $=$ Ri - (bi (Rnir - Minnir))

Dimana :

R'i = Nilai kanal i setelah direduksi

$\mathrm{Ri} \quad=$ Nilai kanal i awal

bi $\quad=$ Besarnya kemiringan regresi

Rnir $\quad=$ Nilai kanal NIR

Minnir $=$ Nilai minimal kanal NIR

Selanjutnya dilakukan Cropping atau pemotongan pada citra bertujuan untuk menyesuaikan dengan lokasi penelitian yang diinginkan.

c. Masking

Setelah dilakukan sunglint, tahap selanjutnya yaitu masking. Masking pada citra bertujuan untuk menampilkan objek yang dominan atau untuk memisahkan objek. Dalam proses ini dibutuhkan band yang mampu membedakan darat dan laut dengan sebaik mungkin, dan band 5 (red) mampu melakukannya karena memiliki respon spektral yang sangat kontras, karena itu pada proses ini digunakan band 5 (red).

\section{d. Lyzenga}

Proses pengolahan lyzenga dilakukan untuk memisahkan substrat yang terdapat diperairan. Citra worldview-2 yang sebelumnya telah melewati tahap koreksi radiometrik hingga sunglint dilanjutkan dengan masking daratan dan laut dalam. Menggunakan sen2cor pada Snap dilakukan masking awan menggunakan LandCloudWhiteCapMask Processor dengan memilih source band 1-5 dan referensinya band 6 . Selanjutnya dibentuk polygon untuk sampel laut dangkal untuk "dangkal" dan sampel laut dalam untuk "dalam". Kemudian dilakukan lyzenga source band 3 dan 4 dengan mengisi berdasarkan polygon yang telah dibentuk untuk dilanjutkan dengan Unsupervised Classification yang berguna untuk mendapatkan hasil klasifikasi dari perairan yang selanjutnya di export dan diolah di Arcgis.

\section{e. Uji Akurasi}

Nilai Intreclass Correlation Coefficient (ICC) adalah statistik uji reliabilitas terhadap satu variabel yang sama dengan skala kontinu yang dilakukan pengukuran dengan dua atau lebih alat pengukur yang berbeda. Nilai ICC adalah varians objek terhadap varian total. Nilai ICC berkisar dari 0 sampai 1 ( $0 \leq$ ICC $\leq$ 1) (Zaki, 2007 didalam Ismunarti (2020). Selain menggunakan ICC uji akurasi lainnya dilakukan dengan menggunakan nilai RMSE (root mean square error). RMSE ialah akar dari rata-rata jumlah kudrat nisbah dimana selisih nilai kedalaman saat di lapangan dengan hasil pengolahan citra. Semakin kecil nilai RMSE maka akan semakin baik (Nurkhayati et al., 2013).

\section{HASIL DAN PEMBAHASAN}

\section{Pasang Surut}

Hasil pengukuran pasang surut di lokasi penelitian diperoleh dari data pasut publikasi BIG stasiun Karimunjawa selama 29 hari yaitu pada tanggal 1 November 2019 sampai dengan tanggal 29 November 2019 yang dilanjutkan untuk analisa dengan metode Admiralty. Pengolahan pasang surut menggunakan metode Admiralty bertujuan untuk mendapatkan komponen pasang surut yang dilanjutkan dengan melakukan perhitungan untuk memperoleh nilai MSL (Mean Sea Level), LLWL (Lowest Low Water Level) dan HHWL (Highest High Water Level). Nilai - nilai komponen pasut ini dan juga nilai pasut 
pada saat perekaman citra akan digunakan sebagai data untuk melakukan koreksi dengan data hasil pengukuran kedalaman.
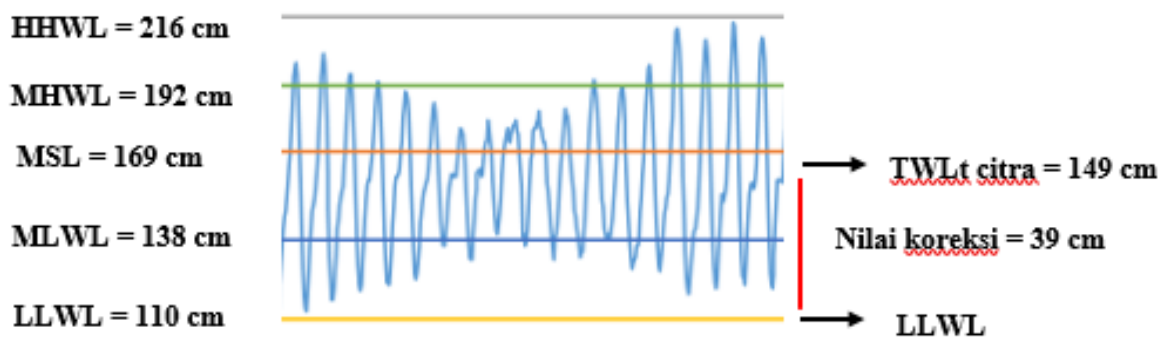

Gambar 3. Koreksi Pasut Untuk Data Kedalaman Pada Saat Perekaman Citra dan Berdasarkan Nilai LLWL.

\section{Pemodelan Kedalaman Perairan}

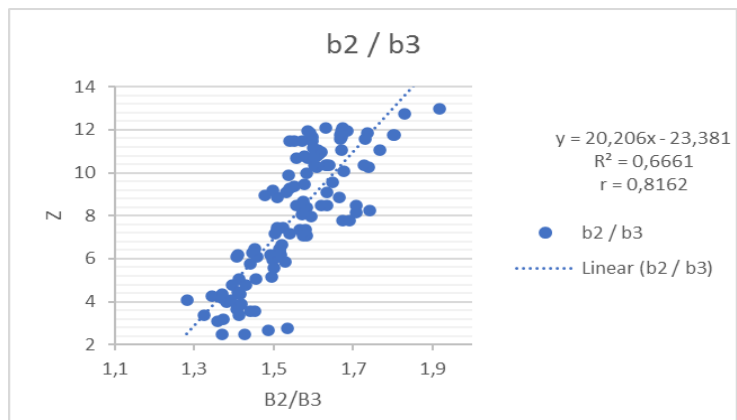

Gambar 4. Grafik Regresi Band 2 / Band 3 terhadap Kedalaman Pada Saat Kondisi Pasut Perekaman Citra.

Hasil dari grafik regresi kombinasi 4 band dengan total masing - masing 8 band rasio pada saat kondisi pasut perekaman citra. Kombinasi algortima band terbaik tesebut yaitu Band 2 / Band 3 dengan nilai koefisien korelasi (r) yaitu 0.8162 dan $\mathrm{y}=20.206 \mathrm{x}-23.381$.

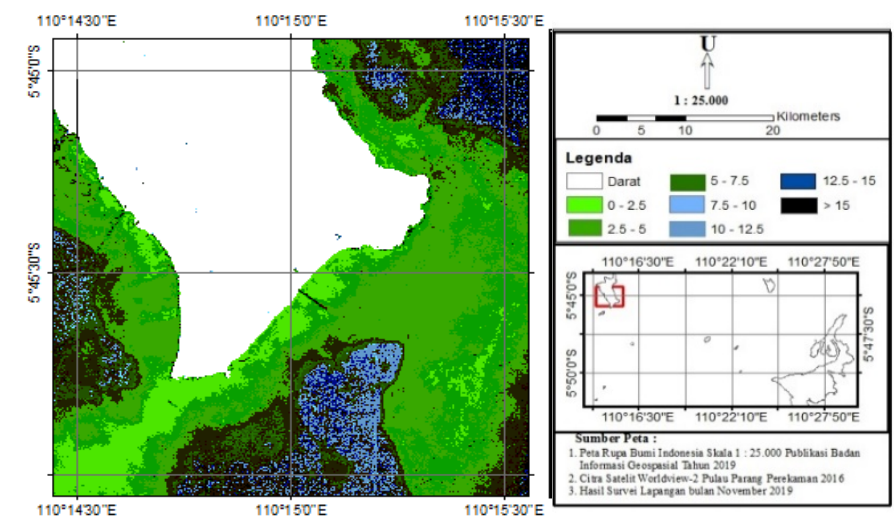

Gambar 5. Peta Batimetri Hasil Pemodelan Band 2 / Band 3

Proses pengambilan data lapangan ditemukan kedalaman di perairan dari $0-32 \mathrm{~m}$. Sementara itu hasil yang diperoleh dari penelitian ini kedalaman yang dapat terbaca hanya dari $0-18 \mathrm{~m}$. Seperti pada gambar diatas terlihat bahwa daerah berwarna hijau terang hingga hijau pekat ialah kedalaman dari 0 7.5 dimana tergolong dangkal. Untuk yang berwarna biru terang hingga gelap terbaca dari $7.5-15 \mathrm{~m}$ 
dan $>15$ berwarna hitam. Hal ini dikarenakan asumsi yang diambil ialah kedalaman dianggap sama dan substrat yang ada di kedalaman dianggap tidak ada. Selain itu hal ini dikarenakan juga oleh bias citra yang terjadi.
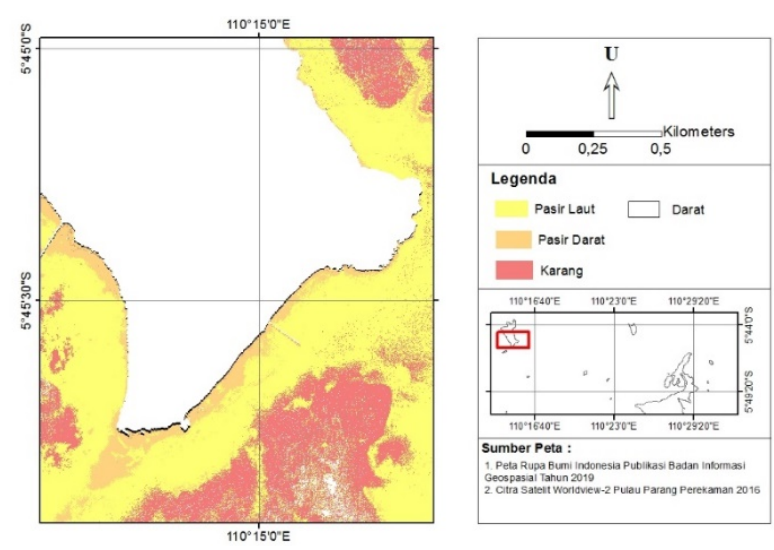

Gambar 6. Peta Hasil Lyzenga Pulau Parang

Berdasarkan hasil pengolahan lyzenga diperoleh 3 klasifikasi yaitu pasir darat, pasir laut dan karang. Dari ketiga kelas habitat tersebut, kelas pasir laut merupakan habitat yang memiliki luasan yang paling besar diantara kelas habitat lainnya. Pasir laut memilik luasan sebesar 265.544637 ha sementara pasir darat hanya seluas 29.003046 ha. sementara itu luasan untuk karang adalah sebesar 92.382743 ha. Hal ini dapat disimpulkan bahwa pada perairan dangkal pulau parang memiliki substrat pasir yang sangat luas.

\section{Uji Akurasi}

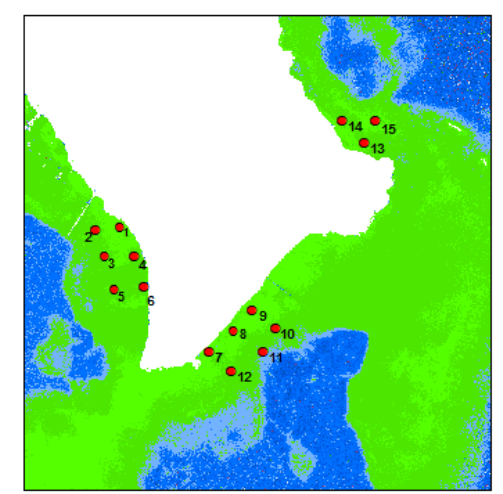

Gambar 7. Peta Titik sampel uji akurasi

Setelah dilakukan uji akurasi antara data lapangan dan data hasil pemodelan maka diperoleh nilai ICC yaitu $61 \%$ dan nilai RMSE sebesar 2.42. Persamaan linear yang digunakan dalam membuat peta batimetri yaitu berdasarkan band biru / hijau dengan nilai koefisien korelasi (r) yaitu 0.8162 . 
Tabel 1. Kedalaman Perairan Hasil Pengukuran Lapangan dan Citra

\begin{tabular}{|c|c|c|c|c|c|}
\hline $\begin{array}{l}\text { Titik } \\
\text { Surv }\end{array}$ & $\begin{array}{l}\text { Pengukuran } \\
\text { Lapangan }\end{array}$ & Citra & $\begin{array}{c}x_{i}=x_{i 1} \\
+x_{i 2}\end{array}$ & $\begin{array}{c}\left(x_{i 1}+\right. \\
\left.x_{i 2}\right)^{2}\end{array}$ & $x_{i 1}^{2}+x_{i 2}^{2}$ \\
\hline ei & $x_{i 1}$ & $x_{i 2}$ & & & \\
\hline 1 & 0.3 & 0.9 & 1.2 & 1.44 & 0.9 \\
\hline 2 & 0.7 & 1.1 & 1.8 & 3.24 & 1.7 \\
\hline 3 & 0.9 & 1.4 & 2.3 & 5.29 & 2.77 \\
\hline 4 & 2.8 & 3.7 & 6.5 & 42.25 & 21.53 \\
\hline 5 & 1.5 & 2.5 & 4 & 16 & 8.5 \\
\hline 6 & 1.8 & 2.1 & 3.9 & 15.21 & 7.65 \\
\hline 7 & 1.7 & 2.0 & 3.7 & 13.69 & 6.89 \\
\hline 8 & 1.9 & 2.4 & 4.3 & 18.49 & 9.37 \\
\hline 9 & 1.4 & 2.2 & 3.6 & 12.96 & 6.8 \\
\hline 10 & 4.2 & 5.4 & 9.6 & 92.16 & 46.8 \\
\hline 11 & 6.6 & 7.2 & 13.8 & 190.44 & 95.4 \\
\hline 12 & 4.0 & 4.6 & 8.6 & 73.96 & 37.16 \\
\hline 13 & 2.1 & 3.1 & 5.2 & 27.04 & 14.02 \\
\hline 14 & 2.0 & 3.3 & 5.3 & 28.09 & 14.89 \\
\hline 15 & 1.8 & 2.9 & 4.7 & 22.09 & 11.65 \\
\hline & 33.7 & 44.8 & 78.5 & 562.35 & 286.03 \\
\hline
\end{tabular}

$$
\begin{aligned}
\text { SS Total } & =286.03-78.5^{2} / 2 \times 15 \\
& =98.62
\end{aligned}
$$

SS Instrumen $=286.03 / 15$

$$
\begin{aligned}
& =14.07 \\
\text { SS Objek } & =(562.35 / 2)-\left(78.5^{2} / 2 \times 15\right) \\
& =281.18-205.41
\end{aligned}
$$$$
=281.18-205.41
$$$$
=75.77
$$

\begin{tabular}{|c|c|c|c|c|}
\hline Sumber Varian & Sum of Square (ss) & Degree of Fredom (df) & Mean Square & Pendugaan Varian \\
\hline & & & & $\sigma^{2}$ \\
\hline SS Instrumen & 14.07 & $2-1=1$ & $\begin{array}{l}14.07 / 2-1= \\
14.07\end{array}$ & 0.9 \\
\hline SS Objek & 75.77 & $15-1=14$ & $\begin{array}{l}75.77 / 15-1= \\
5.4\end{array}$ & 2.4 \\
\hline SS error & 8.78 & $29-1-14=14$ & $8.78 / 14=0.63$ & 0.63 \\
\hline SS Total & 98.62 & $2 \times 15-1=29$ & & \\
\hline $\mathrm{ICC}$ & $\begin{array}{l}=2.4 / 2.4+0 \\
=2.4 / 3.93=\end{array}$ & $\begin{array}{l}+0.63 \\
0.61=61 \%\end{array}$ & & \\
\hline
\end{tabular}

SS Error $\quad=98.62-14.07-75.77$

$$
=8.78
$$

Tabel 2. Pendekatan Analisis Ragam dengan Dua Faktor (ANOVA two way)

Tabel 3. Nilai RMSE Persamaan Fungsi Kedalaman

\begin{tabular}{|c|c|c|}
\hline Persamaan Linear & Band Rasio & RMSE \\
\hline$y=2,2185 x-3,1219$ & B1 / B4 & 4.37 \\
\hline$y=20,206 x-23,381$ & B2 / B3 & 2,42 \\
\hline$y=-49,291 x+39,921$ & B3 / B2 & 4.90 \\
\hline
\end{tabular}

\section{KESIMPULAN}

Berdasarkan hasil penelitian dapat disimpulkan algoritma terbaik yaitu band 1 / band 4 dengan nilai korelasi (r) 0.7059 dengan fungsi regresi $y=2.2185 x-3.1219$, band $2 /$ band 3 nilai korelasi $(r)=0.8162$, dengan fungsi regresi $y=20.206 x-23.381$ dan band 3/band 2 nilai korelasi $(r)=0.7969$ dengan fungsi regresi $\mathrm{y}=-49.291 \mathrm{x}+39.921$. Akurasi terbaik dalam pemetaan kedalaman perairan berdasarkan citra satelit Worldview-2 di perairan Pulau Parang diperoleh oleh band biru / hijau dengan nilai uji akurasi 
menggunakan rumus ICC $=0.61$ atau $61 \%$ dan menggunakan rumus RMSE sebesar 2.42 dan kedalaman laut berdasarkan citra satelit Worldview-2 di perairan Pulau Parang menunjukkan kedalaman dari $0 \mathrm{~m}$ hingga $18 \mathrm{~m}$.

\section{UCAPAN TERIMA KASIH}

Diucapkan terima kasih kepada semua pihak yang telah berkontribusi dalam penelitian ini, sehingga penelitian dapat terlaksana dengan baik.

\section{DAFTAR PUSTAKA}

Arief, M., S. W. Adawiyah., E. Parwati., S. Marpaung. 2017. Metode Dua Kanal untuk Estimasi Kedalaman di Perairan Dangkal menggunakan Data Spot 6 Studi Kasus : Teluk Lampung . Jurnal Penginderaan Jauh, 14(1).

Eugenio, F. IEEE. J, Marcello. and J, Martin. 2015. High-Resolution Maps of Bathymetry and Benthic Habitats in Shallow-Water Environments Using Multispectral Remote Sensing Imagery. IEEE Transactions on and Remote Sensing, 53 (7).

Harianto, K., A. Takwir., Halili. 2019. Pemetaan Batimetri Perairan Dangkal menggunakan Algoritma Jupp pada Citra Spot-7 di Perairan Tanjung Tiram. Sapa Laut 4(1).

Hedley, J. D., A. R. Harborne., and P. J. Mumby. 2005. Simple and Robust Removal of Sunglint for Mapping Shallow-Water Benthos. International Journal of Remote Sensing, 26(10), 21072112.

Hernandez, W. J., and Roy A. A. 2016. Deriving Bathymetry from Multispectral Remote Sensing Data. Journal of Marine Science and Engineering, 4(8).

Hogrefe, K. R. 2005. Deriving Shallow Water Bathymetric Data from Ratios of Blue and Green $\lambda$ Radiance Values. Oregon: Department of Geosciences (Oregon State University).

Ismullah, M. F., M. A. Massinai., Maria. 2018. Shallow Depth Study Using Gravity \& Magnetics Data in Central Java - Yogyakarta. Journal of Physics, Conf. Series 979

Ismunarti, D. H., M. Zainuri., D. N. Sugianto., S. W. Saputra. 2020. Pengujian Reliabilitas Instrumen Terhadap Variabel Kontinu Untuk Pengukuran Konsentrasi Klorofil-a Perairan. Buletin Oseanografi Marina, 9(1), 1-8.

Nugraha, W. A., B. Rochaddi., \& A. Rifai. (2015). Studi Batimetri dan Berkurangnya Daratan Di Wilayah Pesisir Tugu Semarang. Journal of Oceanography, 4(2), 442-450.

Nurdianti, A. K., W. Atmodjo., dan S. Saputro. 2016. Studi Batimetri dan Kondisi Alur Pelayaran di Muara Sungai Kapuas Kecil, Kalimantan Barat. Journal of Oceanography, 5(4), 538-545.

Nurkhayati, R., \& N. Khakhim. 2013. Pemetaan Batimetri Perairan Dangkal Menggunakan Citra Quickbird Di Perairan Taman Nasional Karimun Jawa, Kabupaten Jepara, Jawa Tengah. Jurnal Bumi Indonesia, 2(2).

Shahi, K., Helmi Z.M. Shafri., Ebrahim T., Shattri M., and Ratnasamy M. 2015. A novel spectral index to automatically extract road networks from WorldView-2 satellite imagery. The Egyptian Journal of Remote Sensing and Space Sciences, 27-33

Soeprapto. 2001. Survei Hidrografi. Gadjah Mada University Press. Yogyakarta.

Standar Nasional Indonesia (SNI). 2010. Survei Hidrografi Menggunakan Single Beam. Badan Standar Nasional, Jakarta. SNI 7646:2010, 25 hlm.

Stumpf, R. P., Holderied, K., \& M. Sinclair. 2003. Determination of Water Depth with High-Resolution Satellite Imagery Over Variable Bottom Types. Limnology and Oceanography, 48(1part2), 547-556.

Zaki, R. 2017. Validation of Instrument Measuring Continuous Variable, Advances in Statistical Methodologies and Their Application to Real Problems. Intech open Science. pp: 217-237. 